\title{
El desagravio Monseñor Romero, su pueblo y el papa Francisco
}

\author{
Jon Sobrino \\ Centro Monseñor Romero \\ San Salvador, El Salvador
}

Me han pedido que haga una valoración de la película El desagravio. Me ha encantado. Siempre me da gusto escuchar las palabras de Monseñor Romero y de las personas que vivieron cerca de él. Ver el porte de Monseñor, su rostro, su sonrisa, su cara de preocupación o de disgusto, sus gestos.

También me ha encantado ver a su pueblo, junto a la vía del tren, en la catedral. A sacerdotes, como Mons. Urioste; abogados, como Roberto Cuéllar; a sencillas mujeres que trabajaban en su oficina, como Angelita. A través de todos ellos, conocemos mejor las venturas y desventuras de este pueblo. Y nos enteramos mejor de quién fue Monseñor, qué tuvo que sufrir por ese pueblo, y qué disfrutó con el pueblo.

Al final, aparece el papa Francisco. No es un añadido piadoso, ni un recurso de periodistas, que tienen más a la mano al obispo de Roma. Por el contrario, Francisco es una figura clave en El desagravio. Francisco of rece reparación a Monseñor por los serios agravios que le hicieron y le siguen haciendo personas poderosas, también hermanos obispos.

Tres cosas me han interesado sobremanera: (1) Monseñor fue obispo de un pueblo agraviado; (2) Monseñor sufrió el agravio de la oligarquía y de sus hermanos obispos; y (3) Con ese Monseñor, Dios pasó por El Salvador. Terminaré con una petición sobre su canonización: que haga más presente que su beatificación la palabra de Monseñor y cómo lo invoca su pueblo. 


\section{Una tierra de agravios}

Lo sabemos bien. La tierra de Monseñor ha sufrido infinidad de agravios: niños hambrientos, mujeres violentadas, ancianos abandonados. Comenzó hace siglos, y sigue ocurriendo en formas unas recurrentes y otras cambiantes.

En los últimos cuarenta años, a estos agravios se han añadido otros más novedosos, antes impensables, contra un pueblo cristiano. Nos concentramos en los agravios ocurridos en los tres años del arzobispado de Monseñor. En 1977 fue asesinado el padre Rutilio Grande, con el joven Nelson y el anciano Manuel, dos campesinos inocentes e indefensos. Ese asesinato fue crucial para Monseñor Romero. Mons. Urioste, recientemente fallecido, nos lo ha recordado en la película: "En el funeral había 50,000 personas. Monseñor tuvo una excelente homilía ese día".

Dos meses después, fue asesinado el padre Alfonso Navarro, con otro joven. En 1978, el padre Ernesto Barrera. En 1979, otros tres sacerdotes, entre ellos Octavio Ortiz. Un tanque del ejército pasó sobre su cuerpo y le destrozó la cabeza, cuando estaba con un grupo de jóvenes.

El 24 de marzo de 1980, mataron a Monseñor. Su funeral reunió al mayor número de salvadoreños que se recordaba en aquel entonces. Explotaron bombas, la multitud corría despavorida, buscaba un lugar donde refugiarse. Dentro de la catedral, hermanos norteamericanos, hombres robustos, con sus brazos en alto sostenían a muchos niños, para evitar que murieran asfixiados.

Trágico y triste. Pero los agravios los cometemos los seres humanos. Nada más empezar la película, Mons. Urioste lo dice con toda claridad: "Lo que la oligarquía defendía eran sus propios intereses, naturalmente. Son los dueños del país, que han sido y son herederos de aquellos que vinieron a conquistar el país y también a conquistar sus tierras. Toda la vida se han opuesto a lo que mejore un poco a la gente. Con una actitud de opresión, de maltrato, de desprecio a la gente".

¡Desagravio! Palabra bien elegida para remitirnos a la persona de Monseñor. Pero antes que a él, para remitirnos a la tierra, donde vivió, trabajó y murió.

\section{Monseñor sufrió el agravio de oligarcas y obispos}

A Monseñor Romero, la oligarquía lo insultó y lo difamó de forma aberrante. "Monseñor Romero vende su alma al diablo", "Un día de estos harán exorcismos a Monseñor Romero", se leía en los periódicos. Y la oligarquía no solo lo insultaba, sino que, además, destruía los instrumentos que usaba, en su apostolado, sobre todo, la emisora de la arquidiócesis, varias veces interferida y dinamitada. En la película escuchamos su denuncia del 9 de marzo de 1980, dos semanas antes de su asesinato: "Dañaron la radio del arzobispado. Privaron a la Iglesia de un medio importante de comunicación". Y con profunda delicadeza se dolía del daño mayor: "Perjudicaron más a los desamparados de la ley, a los oprimidos, 
pues les quitaron uno de los pocos medios de información veraz en este país, con una prensa obsecuente, desinformadora, por su propia naturaleza oligarca".

Sorprendente, pero imposible de ocultar, es cómo ofendieron a Monseñor varios de sus hermanos obispos. Mons. Urioste recuerda el hecho y la razón: "Con su postura, se atrajo las críticas de los obispos compañeros suyos. Lo censuraban, lo criticaban, escribían a Roma diciendo sobre él tantas cosas". La postura de la que habla Mons. Urioste consistía en que Monseñor se enfrentaba al gobierno y a los oligarcas, exigía justicia, reparación y verdad. Todo ello para defender a un pueblo pobre y oprimido.

En su último retiro espiritual, un mes antes de su asesinato, Monseñor abrió su conciencia a su padre espiritual, el jesuita Segundo Azkue, y le manifestó las tres cosas que le preocupaban. "No ser tan cuidadoso como antes con mi vida espiritual", expresión de suma delicadeza espiritual, y quizás de cierta tendencia al escrúpulo. "Me cuesta aceptar una muerte violenta, que en estas circunstancias es muy posible", convicción que iba creciendo en él, con lucidez y sin masoquismo. "Mi situación conflictiva con los otros obispos", la preocupación que ahora nos atañe.

La inquina de los obispos del país se mantuvo, aun después de su muerte. A su entierro solo se hizo presente Mons. Rivera, fiel amigo y colaborador. Los obispos ausentes fueron Mons. Aparicio, Mons. Álvarez, Mons. Barrera y Mons. Revelo. Sobre este último, varias veces le he oído contar a Mons. Urioste, con verdad y serenidad, que en 1996, ante Juan Pablo II de visita en el país, dijo: "Romero es el responsable de los 70,000 muertos que se dieron en este país". Otros obispos, por el contrario, dijeron que "debería estar en los altares". Así lo contó Mons. Urioste, quien estuvo presente en el almuerzo. Y me lo confirmó otro sacerdote, que también estuvo presente.

Se comprenderá cuán importante era para Monseñor Romero que en Roma estuvieran bien informados sobre la realidad sufriente del país y cuál era su actuación personal. Por esta obvia razón, después del asesinato de Rutilio Grande, fue a Roma. En palabras de Mons. Urioste: "Monseñor Romero, en su primer viaje a Roma, a finales de marzo del 77, fue para visitar al papa Pablo VI, [pues] ya sabía que había esa animosidad en contra de él". Mons. Urioste lo acompañó. Y prosigue: "Monseñor se encontró con un papa que lo comprendió, que lo entendió. Terminó agarrándole la mano y diciéndole: 'Coraggio. Siga adelante, justed es el que manda!"”.

También con otros obispos y cardenales del Vaticano tuvo experiencias dolorosas. A título personal, quiero añadir que entre los cardenales de la curia vaticana, el cardenal López Trujillo fue un adversario suyo declarado, que en su antagonismo podía llegar a la grosería. Con el cardenal Baggio, prefecto de la Congregación de Obispos, tras un buen comienzo, tuvo momentos de gran 
tensión. Las claras denuncias de Mons. Romero contra el gobierno, la oligarquía y los militares salvadoreños, al Vaticano le causaban problemas diplomáticos con el gobierno de El Salvador, y pronto, con el de Estados Unidos. Monseñor escribe en su diario, comedidamente, que el cardenal Cassaroli le "reveló que el embajador de Estados Unidos había venido a verlo con cierta preocupación de que yo estuviera en una línea revolucionaria".

Cuánto sufrió en su primera visita al papa Juan Pablo II; testigo de ello es María López Vigil. Solo quiero añadir que Juan Pablo II, en su primer viaje a El Salvador, en 1983, mostró respeto y admiración por Monseñor. Se arrodilló ante su tumba en la catedral.

Al final de la película, escuchamos unas palabras recientes del papa Francisco, realmente sorprendentes:

El martirio de Monseñor Romero no fue puntual en el momento de su muerte, porque una vez muerto - yo era sacerdote joven y fui testigo de eso-, una vez muerto, fue difamado, calumniado, ensuciado. O sea que su martirio se continuó incluso por hermanos suyos en el sacerdocio y en el episcopado.

Tristemente, estas palabras confirman un hecho fundamental: lo que le hicieron sufrir sus hermanos obispos. Pero animan, pues un obispo, el de Roma, dice la verdad y expresa su gran aprecio por Monseñor.

En lo personal, no olvido lo que ocurrió en los días finales de Puebla. Nos juntamos un grupo de teólogos y científicos sociales con los obispos más entregados a los pobres. Entre ellos estaba Mons. Romero. La reunión fue muy fraternal. Monseñor habló con varios obispos, y al final se me acercó: "Padre, qué bueno. ¿Por qué no podemos tratarnos así, fraternalmente, los obispos en El Salvador?". Estaba emocionado, casi, casi a punto de llorar.

\section{3. "Con Monseñor Romero, Dios pasó por El Salvador"}

Monseñor siempre fue un hombre y un sacerdote bueno. Pero Medellín, en manos de algunos sacerdotes a veces demasiado entusiastas, lo asustó. Empezó a sonar y a comportarse como un conservador. La reacción de Mons. Urioste ante su nombramiento como arzobispo es clara en la película: "Yo no fui a su toma de posesión porque no consideraba honesto estar allí, no estando yo de acuerdo en aceptar su nombramiento de arzobispo".

La cercanía a la dramática pobreza de la gente, ya en Santiago de María, y, sobre todo, el asesinato de Rutilio Grande hicieron nacer a otro Monseñor. Unos hemos hablado de conversión, otros de cambio radical. El pueblo habló de milagro. Y lo precisó: "es el milagro de Rutilio Grande". Lo acaba de recordar el papa Francisco a Rodolfo Cardenal, en octubre del año pasado (2015). 
Lo que más me agrada de El desagravio es ver cómo va desgranando ese milagro. Mis primeras palabras, después de su asesinato, fueron: "Monseñor Romero creyó en Dios". Al final de la película, Mons. Rafael Urrutia cita las palabras de Ignacio Ellacuría, en el funeral de la UCA: "Con Monseñor Romero, Dios pasó por El Salvador”. Ese Monseñor Romero, con Dios y con su pueblo a cuestas, es el que aparece en la película. Sus palabras son siempre impresionantes, verdaderas, sanadoras de mentira y sufrimiento, y parteras de verdad y esperanza. Me voy a fijar en tres momentos que quiero ponderar.

El primero es una homilía casi de los comienzos, el 30 de octubre de 1977. Había sido una semana trágica. Monseñor celebró la eucaristía por un joven que trabajaba por el pueblo y fue asesinado. Por celebrar esa eucaristía, fue acusado de hacer política. Monseñor desenmascaró la mentira y se defendió con estas palabras: "El pastor tiene que estar donde está el sufrimiento". Y defendió a los campesinos con palabras enternecedoras, sobre todo, para personas como yo, que solo uso el lenguaje de la ciudad, no el del campo.

¿Qué pecado hay en que un pobre cortador de café o de caña, o de algodón, con hambre, pida ocho cucharadas de sopa, un huevo, una comida que apenas le reponga las energías que gasta para ayudar a levantar esas cosechas?

El segundo momento se extendió a todo lo largo de tres años. "La vida es sagrada aun en el más humilde de los campesinos". "No debería haber hombres de primera clase y hombres de segunda clase". "La causa principal de estos problemas es la injusticia social". "Yo denuncio, sobre todo, la absolutización de la riqueza. Ese es el gran mal de El Salvador: la riqueza, la propiedad privada como un absoluto intocable. Y jay! del que toque ese alambre de alta tensión: ¡Se quema!". "Esa sangre, la muerte, toca el corazón mismo de Dios", lo dijo una semana antes de su asesinato. "La violencia, el asesinato, la tortura, donde se quedan tantos muertos, el machetear y tirar al mar, el botar gente; todo esto es el imperio del infierno". Es una de sus letanías más solemnes acerca del horror del país, del 1 de julio de 1979.

El tercer momento son las palabras finales de su última homilía, en la catedral, en la víspera de su asesinato. Esa homilía es la más conocida, la más directa y la más dura. Es la más popular, "en nombre del pueblo". Y es la más teologal, "en nombre de Dios". Antes de sus palabras finales, refiriéndose a la UCA, Monseñor dijo lo siguiente:

Un dato final con el cual queremos expresar una solidaridad especial. Ayer por la tarde, la UCA, Universidad "José Simeón Cañas", fue atacada por primera vez y sin ninguna provocación. Un buen equipo bélico tomó ese operativo a la 1:15 de la tarde, con la Policía Nacional, ingresaron al campus disparando, y un estudiante que se encontraba estudiando matemáticas, Manuel Orantes Guillén, fue asesinado. Me dicen también que han desaparecido varios 
estudiantes y que sus familiares y la UCA protestan por el allanamiento de un campo que debe hacerse respetar por su autonomía. Lo que no han hecho en la universidad nacional, sin duda por temor, lo han hecho en la UCA; con lo cual muestran también que la UCA no está armada para defenderse y que ha sido un atropello sin motivo alguno.

Monseñor prosiguió: "Yo quisiera hacer un llamamiento de manera especial a los hombres del ejército, y en concreto a las bases de la Guardia Nacional, de la policía, de los cuarteles". Y "se dirige directamente" a los que cometen con sus manos el mayor pecado.

Hermanos, son de nuestro mismo pueblo, matan a sus mismos hermanos campesinos, $y$, ante una orden de matar que dé un hombre, debe de prevalecer la ley de Dios que dice: "No matar". Ningún soldado está obligado a obedecer una orden contra la ley de Dios. Una ley inmoral, nadie tiene que cumplirla. Ya es tiempo de que recuperen su conciencia y que obedezcan antes a su conciencia que a la orden del pecado.

Los homicidas siguen siendo "hermanos" que "matan" a sus hermanos. "No hay que obedecer" a una ley inmoral. Hay que recuperar "la conciencia".

La Iglesia, defensora de los derechos de Dios, de la ley de Dios, de la dignidad humana, de la persona, no puede quedarse callada ante tanta abominación Queremos que el gobierno tome en serio que de nada sirven las reformas si van teñidas con tanta sangre.

La Iglesia "no puede callar".

En nombre de Dios, pues, y en nombre de este sufrido pueblo, cuyos lamentos suben hasta el cielo cada día más tumultuosos, les suplico, les ruego, les ordeno, en nombre de Dios: ¡cese la represión!

En el momento más solemne de su predicación, Monseñor "unifica a Dios y al pueblo sufriente".

\section{Mi petición: una canonización más romeriana y más salvadoreña}

Indudablemente, en la ceremonia de canonización se hablará sobre Monseñor Romero. Ante ello, tengo una doble petición. La primera es que en ella se deje hablar a Monseñor y a personas que lo conocieron de cerca, ya sea que todavía estén vivas, o a través de lo que dejaron escrito sobre él, si ya han fallecido. En definitiva, quien mejor habla sobre Monseñor es el mismo Monseñor.

El desagravio of rece espléndidas palabras suyas, muy útiles para ubicarnos en nuestra realidad actual. A ellas quiero añadir otras que ubican nuestra esperanza:

Muchas veces me lo han preguntado en El Salvador. ¿Qué podemos hacer? ¿No hay salida para la situación de El Salvador? Y yo, lleno de esperanza y 
de fe, no solo con una fe divina, sino con una fe humana, creyendo también en los hombres, digo: ¡Sí hay salida!

Ellacuría comprendió bien estas palabras difíciles de entender. Decía que Monseñor apoyaba su esperanza en un pilar trascendente, Dios, y "en un pilar histórico, que era su conocimiento del pueblo al que él atribuía una capacidad inagotable de encontrar salidas a las dificultades más graves".

Con esta esperanza, el 7 de enero de 1979, domingo de una semana que había sido trágica, dijo solemne y majestuosamente: "Sobre estas ruinas brillará la gloria del Señor".

Mi segunda petición es que en la ceremonia de canonización se reconozca el nombre que el pueblo salvadoreño ha dado a Monseñor desde el principio. Y que quede claro que es el pueblo el que lo bautizó después de su muerte.

Hace un año, en la ceremonia de beatificación, se leyó la proclamación apostólica, en la que, entre otras cosas, se dice: "y que en adelante se le llame beato". Si no cambian las cosas, en la canonización se dirá: "y que en adelante se le llame santo". Si se me permite el asombro ante estas palabras que se refieren a Monseñor, solo diré: "Tarde llegan actas de tierras lejanas".

Entre nosotros, las primeras palabras de Pedro Casaldáliga, después del asesinato, fueron: "San Romero de América, pastor y mártir nuestro". Y en la noche del asesinato, unas sencillas mujeres exclamaron: "Han matado al santo".

El poema de don Pedro Casaldáliga concluye: "nadie hará callar tu última homilía". Mi deseo es que nos apuntemos todos a estas palabras y trabajemos para que sean cada vez más reales.

Y ojalá, creyentes y no creyentes, cada uno a su manera, escuchemos y pongamos a producir las palabras que dijo Monseñor al final de su vida. Ponen en íntima relación lo que fue último para él, su Dios, y lo que fue igualmente último, los pobres de su pueblo. Dijo: "La gloria de Dios es que el pobre viva". Que lo que Monseñor ha unido no lo separemos los hombres. 